\title{
IMPLEMENTASI KENDALI LQR UNTUK PENGENDALIAN SIKAP LONGITUDINAL PESAWAT FLYING WING
}

\author{
IMPLEMENTATION OF LQR CONTROL FOR THE \\ LONGITUDINAL ATTITUDE STABILITY OF FLYING WING \\ AIRCRAFT
}

\author{
Try Susanto ${ }^{1}$, Sampurna Dadi Riskiono $^{2}$, Rikendry $^{3}$, Andi Nurkholis ${ }^{4}$ \\ ${ }^{1234}$ Universitas Teknokrat Indonesia
}

\begin{abstract}
${ }^{1}$ try_susanto@teknokrat.ac.id, ${ }^{2} \underline{\text { sampurna.go@ @ teknokrat.ac.id }}, \underline{{ }^{3} \text { ken@teknokrat.ac.id, }}$ andinh@teknokrat.ac.id
\end{abstract}

\begin{abstract}
Abstrak
Perkembangan pesawat tanpa awak dalam beberapa tahun terakhir menjadi perhatian banyak pihak dan menarik banyak peminat. Pesawat tanpa awak telah banyak digunakan untuk berbagai misi, diantaranya adalah untuk pemetaan wilayah dan militer. Bentuk pesawat tanpa awak yang relative kecil, menjadikan sensitive terhadap gangguan lingkungan terutama angin, hal tersebut dapat menyebabkan pesawat kehilangan kestabilan dan mengalami stall, sehingga menggagalkan misi penerbangan. Oleh karena itu diperlukan sistem kendali yang yang kuat dan cepat untuk mengatur konfigurasi gerak agar tidak terjadi stall. Pada penelitian ini metode kendali LQR diterapkan untuk mengendalikan sudut roll pada pesawat agar mampu mempertahankan kestabilan sikap longitudinal. Berdasarkan hasil pengujian yang telah dilakukan, metode kendali LQR mampu mengendalikan sudut roll pesawat sehingga pesawat mampu mempertahankan kestabilan sikap longitudinal, terbukti ketika sudut roll diberikan gangguan, terjadi overshoot sebesar $4,28^{\circ}$, namun pesawat dengan cepat mampu kembali ke keadaan semula dengan rise time 0,7 detik, setling time 1,3 detik dan kecendrungan steady state error sebesar $1,37^{\circ}$
\end{abstract}

Kata kunci : Unnamed Aerial Vehicle, Longitudinal, LQR, Steady State Error

\begin{abstract}
Unmanned Aerial Vehicle (UAV) deveploment has attracted the attention of many parties and attracted a lot of enthusiasts recently. Unmanned Aerial Vehicle (UAV) have been widely used various missions, including regional and military mapping. The shape of drone relatively small making it sensitive to environmental distrubances, especially the wind, this can cause the aircraft to lose stability and stall, thus thwarting missions. Therefore, a strong and fast control system is needed to adjust the motion configuration so that it does not stall. In this research, the LQR control method is applied to control the roll angle of aircraft in order to able to maintain longitudinal stability. Based on the results of the tests that have been carried out, the LQR control method is able to control the roll angle of the aircraft so that the aircraft is able to maintain the stability of its longitudinal stance, it is proven that when the roll angel is disturbed, there is an overshoot of $4,28^{\circ}$. But the aircraft can quickly return to its original state with a rise time of 0.7 seconds, the setting time is 1.3 seconds and the tren is steady state error of $1.37^{\circ}$
\end{abstract}

Keywords: Unnamed Aerial Vehicle, Longitudinal, LQR, Steady State Error 


\section{PENDAHULUAN}

Kemajuan teknologi dewasa ini telah memasuki berbagai segi kehidupan, khususnya bidang pesawat tanpa awak. Perkembangan pesawat tanpa awak menjadi perhatian banyak pihak dan menarik banyak peminat, karena sistemnya portable dan bentuknya relatif kecil menjadikan pesawat ini mudah untuk dibawa. Pesawat tanpa awak telah banyak digunakan untuk berbagai misi, diantaranya adalah untuk pemetaan wilayah dan militer [1][2][3]. Pengendalian pesawat tanpa awak dapat dilakukan secara manual dan secara autopilot. Pesawat tanpa awak memiliki beberapa tipe yang berbeda, salah satu yang banyak digunakan adalah tipe pesawat flying wing. Pesawat flying wing memiliki bentuk segitiga dengan dilengkapi servo pada sisi kiri dan kanan sayapnya, selain itu pesawat ini tidak memiliki ekor (tailless) yang menjadikan konfigurasi pesawat ini sederhana [4]. Pengendali utama untuk naik turun dan belok kiri kanan pada pesawat jenis ini adalah elevon, dan dilengkapi dengan motor brushless sebagai pendorongnya. Pesawat jenis flying wing memiliki kemampuan gliding yang sangat baik, sehingga mampu terbang menjelajah jauh secara efektif dengan membawa muatan [5].

Bentuk pesawat tanpa awak yang relatif kecil, menjadikan sensitif terhadap gangguan lingkungan terutama angin. Hal ini dapat menyebabkan pesawat kehilangan kestabilan terbang dan menjadikan pesawat stall, sehingga dapat menggagalkan misi penerbangan. Stall adalah kondisi sudut serang pesawat meningkat melebihi sudut kritis. Sudut kritis yang dapat menyebabkan pesawat tanpa awak mengalami stall adalah besar dari $25^{\circ}$ [6]. Keadaan ini menyebabkan pesawat berputar (spinning), dan memerlukan waktu yang relatif lama untuk memulihkan pesawat ke kondisi semula [7]. Permasalahan tersebut dapat diantisipasi ketika terbang secara manual, namun ketika terbang secara autopilot permasalahan tersebut menjadi hal yang sangat fatal. Oleh karena itu pesawat tanpa awak memerlukan sistem kendali untuk mengatur konfigurasi gerak dalam menjaga kestabilan sikap terbang untuk mecegah terjadinya stall. Salah satu faktor yang mempengaruhi kestabilan sikap terbang pada pesawat adalah pengendalian sikap longitudinal. Kestabilan sikap longitudinal dipengaruhi oleh sudut roll, dan pergerakan pada sumbu ini disebut gerak rolling. Gerak rolling dicapai dengan membelokkan aileron dikedua sayap kearah yang saling berlawanan. Pengendalian sudut roll pada pesawat merupakan hal penting yang harus dilakukan, karena berpengaruh terhadapa kestabilan sikap longitudinal pesawat [8]

Beberapa penelitian telah dilakukan berkaitan dengan pengendalian sudut roll untuk menjaga stabilitas sikap longitudinal pesawat, seperti yang dilakukan Mbaocha [9], dalam penelitiannya menerapkan metode kendali PID (Proporsional Integral Derivatif) untuk mengendalikan sudut roll pada pesawat. Metode kendali yang diterapkan berhasil mengendalikan sudut roll dan membuat pesawat mencapai kestabilan sikap, namun masih menghasilkan overshoot yang besar serta waktu penyelesaian yang relative lama. Erwhin Irmawan [10] menggabungan metode adaptif neuro fuzzy dan PID untuk mengendaikan kestabilan sikap longitudinal pesawat tanpa awak, penggabungan kedua metode tersebut berhasil membuat respon sistem dan waktu penyelesaiannya menjadi lebih cepat, tetapi overshoot yang dihasilkan cukup besar. Pengendalian sudut roll sangat penting karena berpengaruh terhadap kestabilan sikap longitudinal pesawat, oleh karena itu sistem kendali yang yang kuat dan cepat sangat dibutuhkan untuk pesawat dalam rangka menuju titik kestabilan. Metode kendali yang memiliki kemampuan tersebut salah satunya adalah metode kendali LQR [11]. Metode kendali tersebut telah digunakan oleh [12] untuk mengendalikan sikap terbang pada quadcopter. Penerapan metode terebut berhasil membuat wahana mampu terbang dengan mempertahankan kestabilan sikap. Atas dasar keunggulan yang dimiliki oleh metode kendali tersebut, pada penelitian ini penulis menerapkan metode kendali LQR untuk pengendalian sikap longitudinal pada pesawat flying wing. 


\section{DASAR TEORI /MATERIAL DAN METODOLOGI/PERANCANGAN}

\subsection{Dasar Teori}

Pesawat tanpa awak adalah sebuah wahana yang mampu terbang secara jarak jauh dikendalikan oleh pilot melalui remote kontrol, selain itu mampu terbang secara mandiri menggunakan sistem yang ditanamkan didalamnya. Ada beberapa jenis pesawat tanpa awak, salah satunya adalah pesawat tipe flying wing. Flying wing atau sayap terbang berbentuk segitiga dengan dilengkapi elevon sebagai kendai geraknya. Flying wing memiliki kemampuan gliding diudara, sehingga dapat terbang jauh menjelajah dengan membawa muatan. Ketika terbang, terjadi dua pergerakan sekaligus yang dialami pesawat, yaitu gerak translasi dan gerak rotasi. Model dinamika gerak flying wing dapat dilihat pada gambar 1.

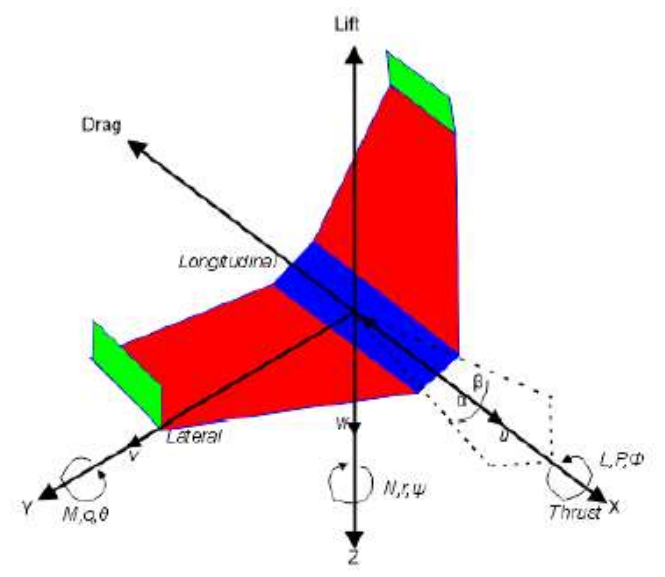

Gambar 1. Dinamika Gerak Pesawat

\subsubsection{Gerak Translasi}

Gerak translasi pesawat terjadi pada tiga sumbu, yaitu vertika, horizontal, dan vertical. Penentuan gerak translasi berkaitan dengan Hukum Newton-Euler berdsarkan hokum kedua Newton. Pergerakan translasi pesawat dituliskan pada persamaan 1 sampai persamaan 3.

$$
\begin{aligned}
& X=(U+Q W-V R+g \sin \theta) \\
& Y=(V+U R-P W-g \cos \theta \sin \phi) \\
& Z=(W+P V-U Q+g \cos \theta \cos \phi)
\end{aligned}
$$

\subsubsection{Gerak Rotasi}

Gerak rotasi pesawat terjadi pada sumbu poros pesawat mengakibatkan terjadinya momentum angulerdengan sudut tertentu. Momentum anguler diturunkan dari persamaan momentum dituliskan pada persamaan 4 samapi persamaan 6 .

$$
\begin{aligned}
& M_{x}=I_{x x} \dot{P}-(\dot{R}+P Q)+\left(I_{z z}-I_{y y}\right) \\
& M_{y}=I_{Y Y} \dot{Q}-(P 2+R 2)+\left(I_{x x}-I_{z z}\right) \\
& M_{z}=I_{z z} \dot{R}-I_{x z}-I_{x x}+R Q I_{x z}
\end{aligned}
$$

\subsection{Metodelogi}

Metode LQR (Liner Quadratic Regulator) adalah metode kontrol berbasis ruang keadaan yang model dan bentuk kontrolernya berupa linier. Metode kontrol ini juga menggunakan hukum umpan balik keadaan. Persamaan persamaan sistem linier dan umpan balik keadaan dituliskan pada persamaan (7) hingga pesamaan (9) 


$$
\begin{aligned}
& \dot{x}=A x+B u \\
& u=C x \\
& u=-K x
\end{aligned}
$$

Metode kendali ini bekerja berdasarkan dua buah parameter yang harus ditentukan, yaitu matrks $Q$ dan $R$ agar diperoleh nilai $\mathrm{K}$ terbaik yang berpengaruh terhadap respon sistem [13]. Pembobotan matriks $\mathrm{Q}$ dan $\mathrm{R}$ dilakukan secara bertahap dimulai dari satu, selanjutnya ditambah ataupun dikurang sesuai dengan respon sistem. Persamaan torsi pesawat flying wing diperoleh dengan menurunkan persamaan (1) hingga persamaan (3), penyesuaian variabel untuk model pada penelitian ini tertulis dalam Table 1

Tabel 1. Penyesuaian Variabel

\begin{tabular}{|c|c|c|}
\hline $\begin{array}{c}\text { Variabel } \\
\text { awal }\end{array}$ & $\begin{array}{c}\text { Variabel } \\
\text { Penyesuaian }\end{array}$ & Keterangan \\
\hline $\mathrm{L}$ & $\tau_{1}$ & Torsi roll \\
\hline $\mathrm{M}$ & $\tau_{2}$ & Torsi pitch \\
\hline $\mathrm{P}$ & $\omega_{\phi}$ & Kecepatan sudut roll \\
\hline $\mathrm{Q}$ & $\omega_{\theta}$ & Kecepatan sudut pitch \\
\hline
\end{tabular}

persamaan gerak rotasi pesawat terhadap sumbu x dan y dapat dituliskan menjadi,

$$
\begin{aligned}
& \tau_{1}=I_{x x} \dot{p}+\left(I_{x z}-I_{y y}\right) \omega_{\theta} r \\
& \tau_{2}=I_{y y} \dot{q}+\left(I_{x x}-I_{z z}\right) \omega_{\phi} r
\end{aligned}
$$

Dimana $I_{x x}$ adalah inersia pada sumbu x pesawat, $I_{y y}$ adalah inersia pada sumbu $\mathrm{y}, \dot{p}$ adalah percepatan sudut roll, $q$ adalah percepatan sudut pitch, dan $\mathrm{r}$ adalah yaw rate. Parameter sistem yang digunakan untuk pengendalian pesawat melibatkan 8 state, yaitu:

- Posisi x kecepatan translasi sumbu $\mathrm{x}\left(v_{x}\right)$

- Posisi y dan kecepatan trasnlasi sumbu y $\left(v_{y}\right)$

- Sudut roll $(\phi)$ dan kecepatan sudut roll $\left(\omega_{\phi}\right)$

- Sudut pitch $(\theta)$ dan kecepatan sudut pitch $\left(\omega_{\theta}\right)$

Sehingga state space sistem dituliskan menjadi:

$$
\left[\begin{array}{l}
U \\
\dot{U} \\
V \\
\dot{V} \\
P \\
\dot{P} \\
Q \\
\dot{Q}
\end{array}\right]=\left[\begin{array}{cccccccc}
0 & 1 & 0 & 0 & 0 & 0 & 0 & 0 \\
0 & 0 & 0 & 0 & 0 & 0 & 0 & 0 \\
0 & 0 & 0 & 1 & 0 & 0 & 0 & 0 \\
0 & 0 & 0 & 0 & 0 & 0 & 0 & 0 \\
0 & 0 & 0 & 0 & 0 & 1 & 0 & 0 \\
0 & 0 & 0 & 0 & 0 & 0 & 0 & \frac{\left(I_{y y}-I_{z z}\right) r}{I_{x x}} \\
0 & 0 & 0 & 0 & 0 & 0 & 0 & 1 \\
0 & 0 & 0 & 0 & \frac{I_{z z}-I_{x x}}{I_{y y}} & 0 & 0 & 0
\end{array}\right]\left[\begin{array}{l}
x \\
v_{x} \\
y \\
v_{y} \\
\phi \\
\omega_{\phi} \\
\theta \\
\omega_{\theta}
\end{array}\right]+\left[\begin{array}{cccc}
0 & 0 & 0 & 0 \\
\frac{1}{m} & 0 & 0 & 0 \\
0 & 0 & 0 & 0 \\
0 & \frac{1}{m} & 0 & 0 \\
0 & 0 & 0 & 0 \\
0 & 0 & \frac{1}{I_{x x}} & 0 \\
0 & 0 & 0 & 0 \\
0 & 0 & 0 & \frac{1}{I_{y y}}
\end{array}\right]\left[\begin{array}{l}
F_{x} \\
F_{y} \\
L \\
M
\end{array}\right]
$$

$\begin{array}{llllll}x= & A & x & B & u\end{array}$ 
Persamaan (13) hingga (15) untk menghitung inersia di masing-masing sumbu

$$
\begin{aligned}
& I_{x x}=\frac{1}{12} m\left(b^{2}+c^{2}\right) \\
& I_{y y}=\frac{1}{12} m\left(a^{2}+b^{2}\right) \\
& I_{z z}=\frac{1}{12} m\left(a^{2}+c^{2}\right)
\end{aligned}
$$

Rancangan diagram sistem kendali LQR seperti pada gambar 2

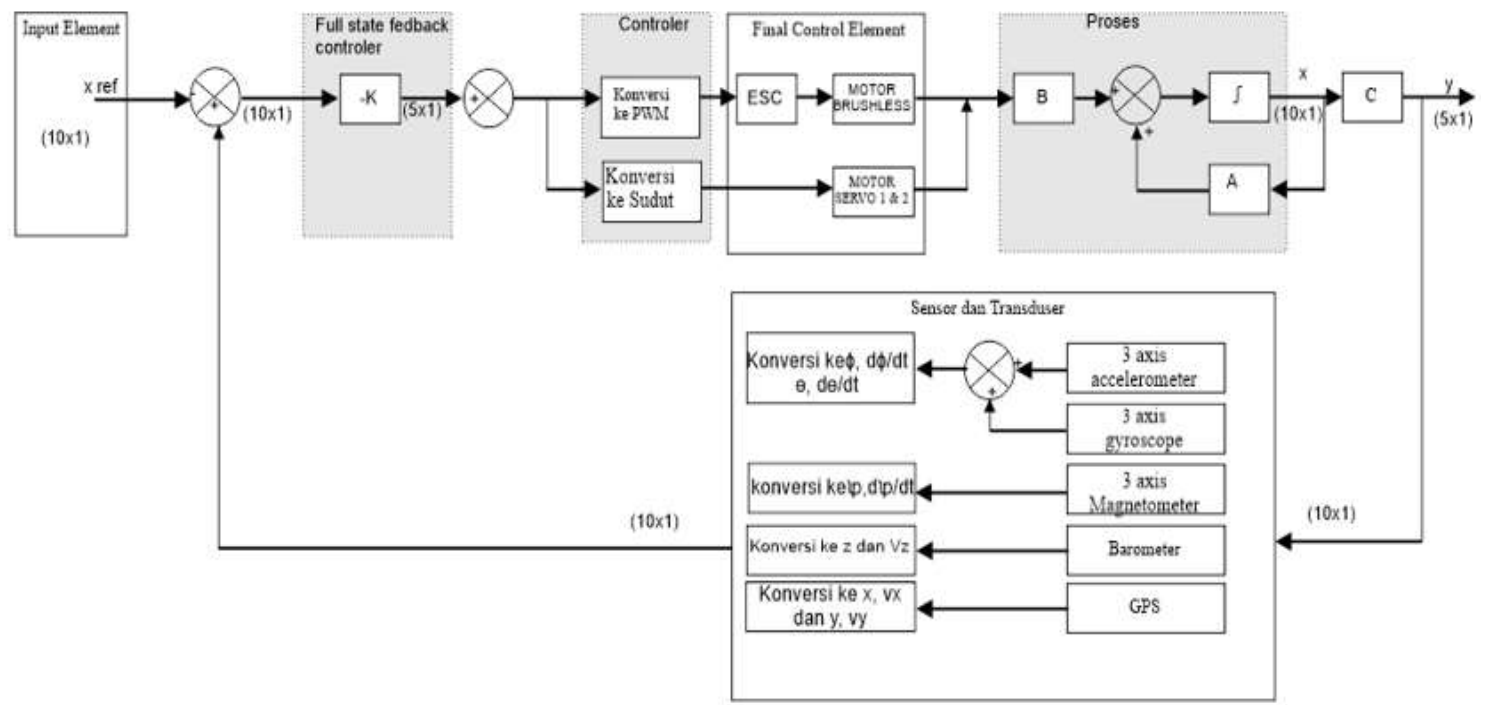

Gambar 2. Rancangan Digram Blok Sistem

\subsection{Perancangan Sistem}

Sistem mekanik pada penelitian ini berupa pesawat jenis flying wing, rancangan bentuk wahana terlihat seperti gambar 3

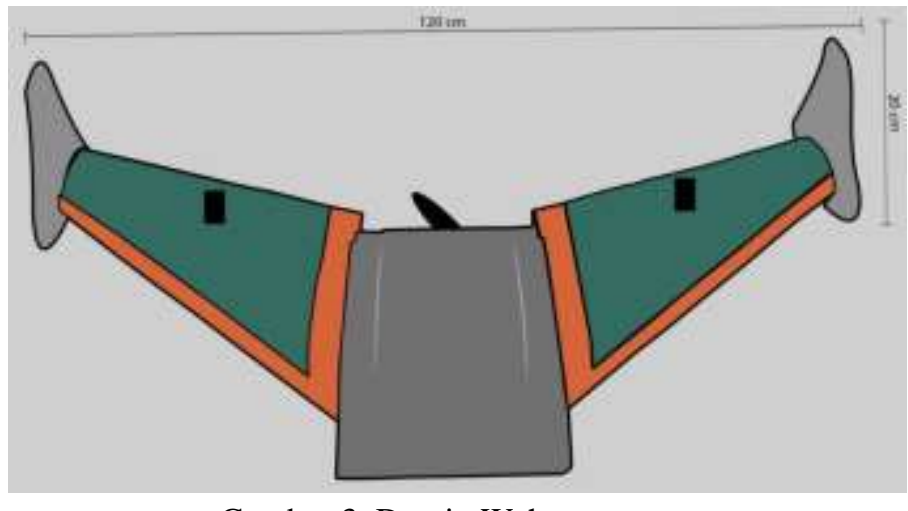

Gambar 3. Desain Wahana

Wahana terbuat dari bahan polyfoam dengan ukuran bentang sayap $120 \mathrm{~cm}$, dan bobot wahana sekita $1 \mathrm{~kg}$. Wahana dilengkapi dengan sebuah motor servo pada masing-masing sayapnya sebagai aktuator pengendali gerak elevon. Elevon berfungsi untuk mengatur gerak maneuver naik-turun serta belok kekiri dan kekanan. Selain itu wahana juga dilengkapi dengan sebuah motor brushless dan sebuah propeller yang berfungsi sebagai pendorong dari gerak wahana. 


\subsection{Perancangan Sistem Elektronik}

Perancangan sistem elektronis terdiri dari beberapa sensor dan receiver yang terhubung ke mikrokontroler .Hubungan antara bagian sistem elektronis pada penelitian ini ditampilkan pada pada gambar 4.

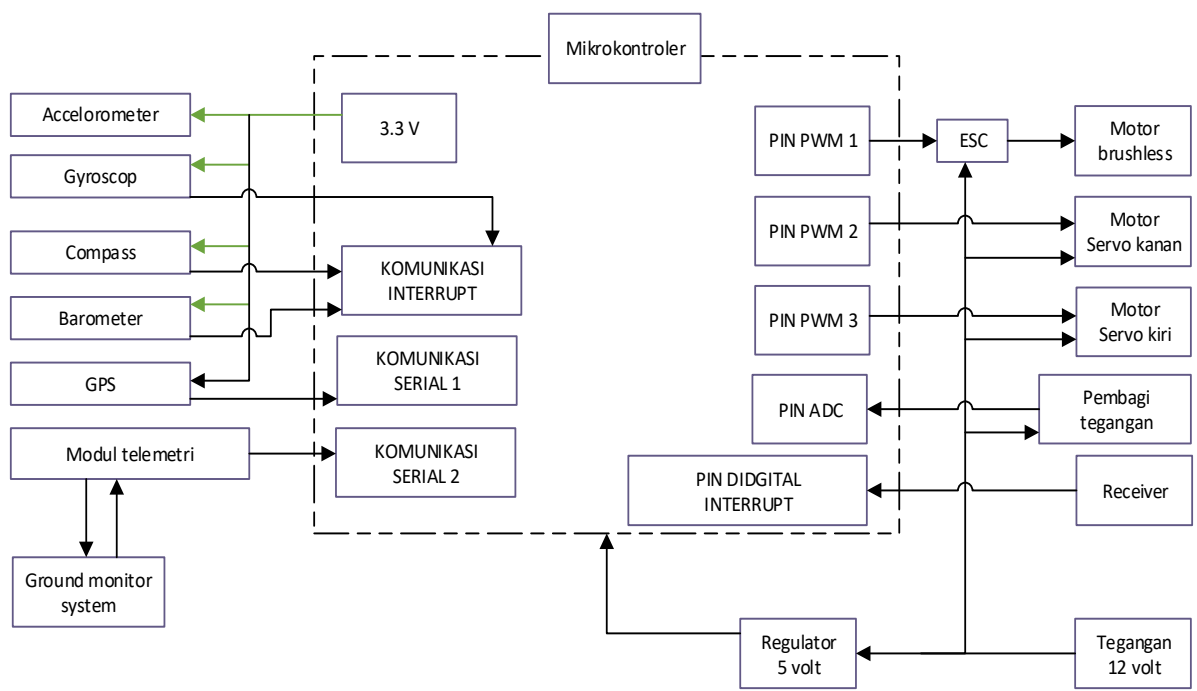

Gambar 4. Arsitektur Sistem

Sensor-sensor yang digunakan dalam sistem elektronik anatara lain akselerometer, giroskop, kompas dan barometer. Sensor akselerometer dana giroskop menghasilkan data berupa sudut roll dan pitch, sedangkaan sensor kompas digunakan untuk mengatur heading serta untuk navigasi pesawat. Sensor barometer digunakan untuk memberikan data ketinggian pesawat. Pada bagian pengolah algoritma digunakan mikrokontroler ARM Cortex-M4 dengan kecepatan komputasi $72 \mathrm{MHz}$. Pada bagian aktuator menggunakan motor brushless dengan spesfikasi 1400 yang berfungsi sebagai pendorong, dan 2 buah servo sebagai kendali elevon.

\subsection{Perancangan Perangkat Lunak}

Perangkat lunak pada penelitian ini menggunakan bahasa pemrograman $\mathrm{C}++$ dengan compiler Arduino IDE. Sistem akan memasuki kondisi awal untuk memulai akses sensor, pembacaan telemetri, remote kontrol, dan aktuator. Selanjutnya, sistem melakukan pengecekan apakah wahana sudah siap untuk diterbangkan dengan mengubah mode pada remote kontroler. Program utama akan memeriksa subprogram yang digunakan untuk membri perintah apakan wahana akan terbang secara manual menggunakan pilot atau terbang secara autopilot. Jika pesawat terbang dengan mode autopilot, maka program akan melakukan perhitungan untuk kondsi yang dikendalikan. Program sistem pesawat utama ditampilkan flowcart pada gambar 5 


\section{Jurnal Electro Luceat [November] [2020]}

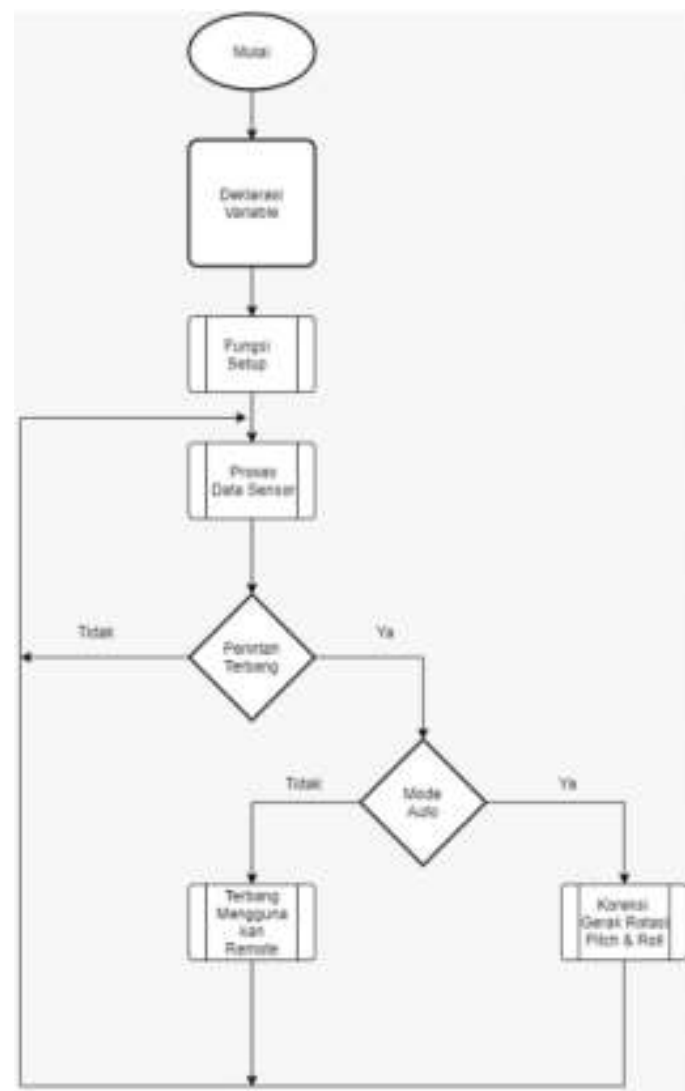

Gambar 5. Flowchart Program

\section{PEMBAHASAN}

\subsection{Implementasi Alat}

Proses implementasi dilakukan dengan membuat wahana berupa pesawat tipe flying wing yang terbuat dari bahan polyfoam dengan bentang pesawat $\pm 120 \mathrm{~cm}$, dengan bobot sekitar $1 \mathrm{~kg}$ dengan sistem elektronis didalamnya. Pesawat dilngkapi dengan actuator berupa motor servo yang terletak pada kiri dan kanan sayap, serta sebuah motor brushless lengkap dengan propeller dibagian belakang pesawat. Bentuk pesawat dapat dilihat pada gambar 6.

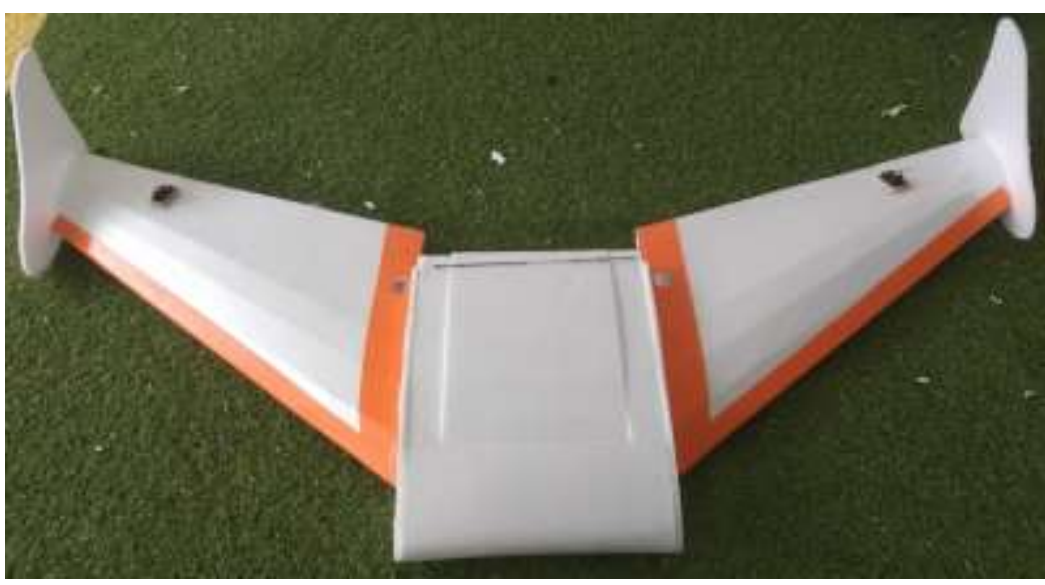

Gambar 6. Pesawat Flying Wing

Implementasi sistem elektronis ditunjukkan pada gambar 7, terdiri dari sensor accelerometer dan gyroskop sebagai pembaca sudut roll dan pitch, modul telemetri sebagai perangkat kirim dan penerima data, receiver remote sebagai penerima perintah terbang secara manual, serta 
mikrokontroler tensy, sebagai pengolah data sensor yang didalamnya ditanamkan perangkat lunak dengan metode kendali LQR

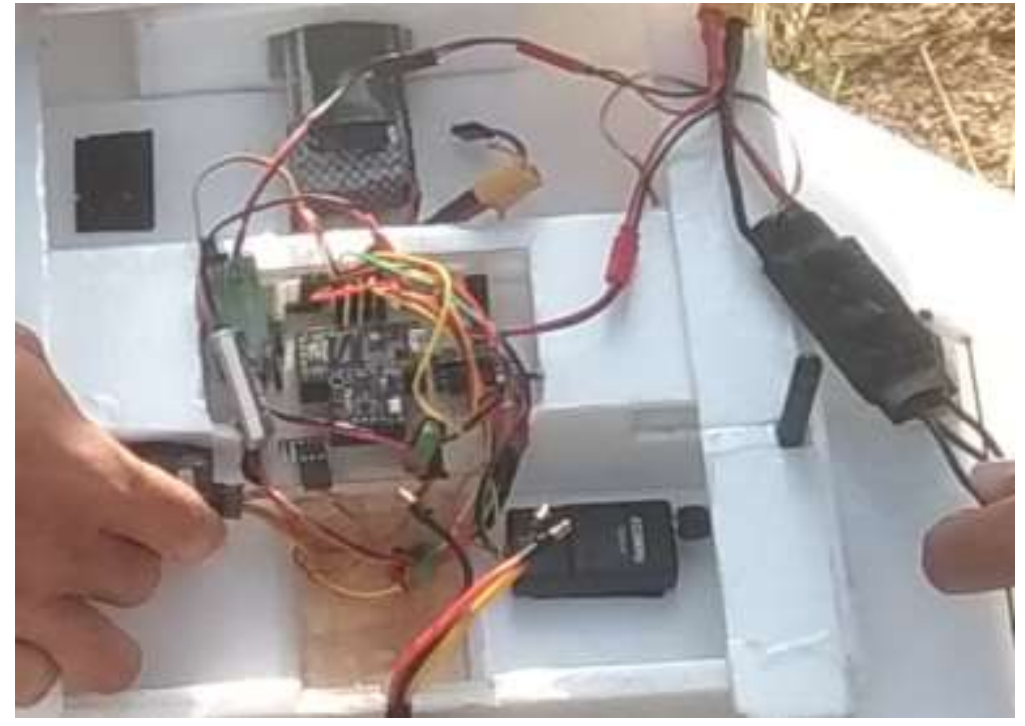

Gambar 7. Implementasi Sistem Elektronis

\subsection{Pengujian Sistem}

Pengujian sistem kendali LQR dilakukan dengan cara menerbangkan pesawat menggunakan remote kontrol untuk mengendalikan kecepatan motor pendorong pesawat, sedangkan pengendalian kestabilan sikap menggunakan algoritma LQR yang telah ditanamkan didalam mikrokontroler. Sebelum pengujian sistem, dilakukan tuning pembobotan nilai konstanta $\mathrm{Q}$ yang bertujuan untuk memperoleh nilai gain umpan balik (feedback) terbaik. Hasil tuning nilai $\mathrm{Q}$ terbaik yang diperoleh ditandai pesawat terbang stabil dengan sudut roll dan pitch mendekati $0^{\circ}$. Hasil nilai tuning $\mathrm{Q}$ yang menghasilkan respon umpan balik K terbaik tersaji pada table 2.

Tabel 2. Tabel Konversi $Q$ ke Gain $K$

\begin{tabular}{|cccccccc}
\hline \multicolumn{10}{|c|}{$Q$} & \multicolumn{8}{|c|}{$K$} \\
\hline$\left[\begin{array}{cccccccccc}0 & 0 & 0 & 0 & 1,01 & 0 & 0 & 0 \\
0 & 0 & 0 & 0 & 0 & 3,92 & 0 & 0\end{array}\right]$ & {$\left[\begin{array}{llllllll}0 & 0 & 0 & 0 & 4,5 & 2,3 & 0 & 0\end{array}\right]$} \\
\hline
\end{tabular}

Hasil tuning terbaik yang diperoleh berdasarkan table 2 adalah 1,01 untuk nilai $Q_{\phi}$ dan 3,92 untuk $Q_{\omega \phi}$, dengan nilai tersebut menghasilkan umpan balik gain K sebesar 4,5 dan mampu membuat pesawat terbang stabil. Penguatan nilai Q berbanding lurus dengan perubahan nilai sudut dan berpengaruh terhadap respon pesawat dalam memepertahan sikap mendekati set point. Semakin besar nilai $\mathrm{Q}$ maka menghasilan nilai umpan bailk gain $\mathrm{K}$ yang besar pula, sehingga perubahan sudut semakin besar dan menyebabkan respon pesawat semakin cepat dalam memperbaiki keadaan, namun dapat menghasilkan overshoot yang besar. Sebaliknya, jika nilai Q kecil, maka menghailkan nilai umpan balik gain K yang kecil pula, sehingga respon pesawat menjadi lambat ketika memperbaiki sikap menuju set point. Pengujian gerak longitudinal pesawat dilakukan dengan memberikan gangguan sebesar $20^{\circ}$ pada sudut roll. Ketika sudut roll pada pesawat diberikan gangguan, terjadilah penyimpangan set point dan terjadi gerak rolling kekiri dan kekanan. Gerakan kekiri kekanan yang terjadi merupakan multi overshoot yang dialami pesawat. Hasil pengujian gerak longitudinal pesawat dimuat pada table 3 . 
JEC Vol. 6 No. 2

Jurnal Electro Luceat [November $]\left[2020^{-}\right.$

Tabel 3. Hasil Pengujian

\begin{tabular}{|c|c|c|c|c|}
\hline \multirow{2}{*}{ Respon Sistem } & \multicolumn{5}{|c|}{ Hasil } \\
\cline { 2 - 5 } & Uji 1 & Uji 2 & Uji 3 & $\begin{array}{c}\text { Spesfikasi } \\
\text { Minimum }\end{array}$ \\
\hline Rise Time (tr) & 0.8 & 0.9 & 0,7 & $<1 \mathrm{~s}$ \\
\hline Settling Time (ts) & 1.7 & 1.5 & 1.3 & $<3 \mathrm{~s}$ \\
\hline Overshoot & 4.46 & 4.33 & 4.28 & $<4.5^{0}$ \\
\hline Undershoot & 2.27 & -3.38 & -3.17 & $>-4.5^{0}$ \\
\hline Steady State Error & 2.88 & 2.78 & 1.37 & $\pm 4.5^{0}$ \\
\hline
\end{tabular}

Setelah dilakukan tiga kali percobaan, respon pesawat secara keseluruhan memiliki karakteristik yang memenuhi spesfikasi minimum. Berdasarkan tabel hasil percobaan, respon terbaik diperoleh pada percobaan ketiga. Sesaat setelah diberikan gangguan, pesawat menyimpang dari setpoint dan mengalami puncak overshoot sebesar 4,28 dengan rise time 0,7 detik, sistem juga mengalami undershoot sebesar $-3,17^{\circ}$. Pesawat memerlukan waktu sebesar 1,3 detik untuk menuju setpoint. Metode kendali yang diterapkan pada pesawat, berhasil meminimalkan meminimalisir gangguan yang diberikan sehingga pesawat mampu mempertahankan kestabilan sikap. Kecendrungan steady state error pesawat dalam mempertahankan sikap sebesar $1,37^{\circ}$. Analisa hasil pengujian respon sistem terbaik ditampilkan pada gambar 3

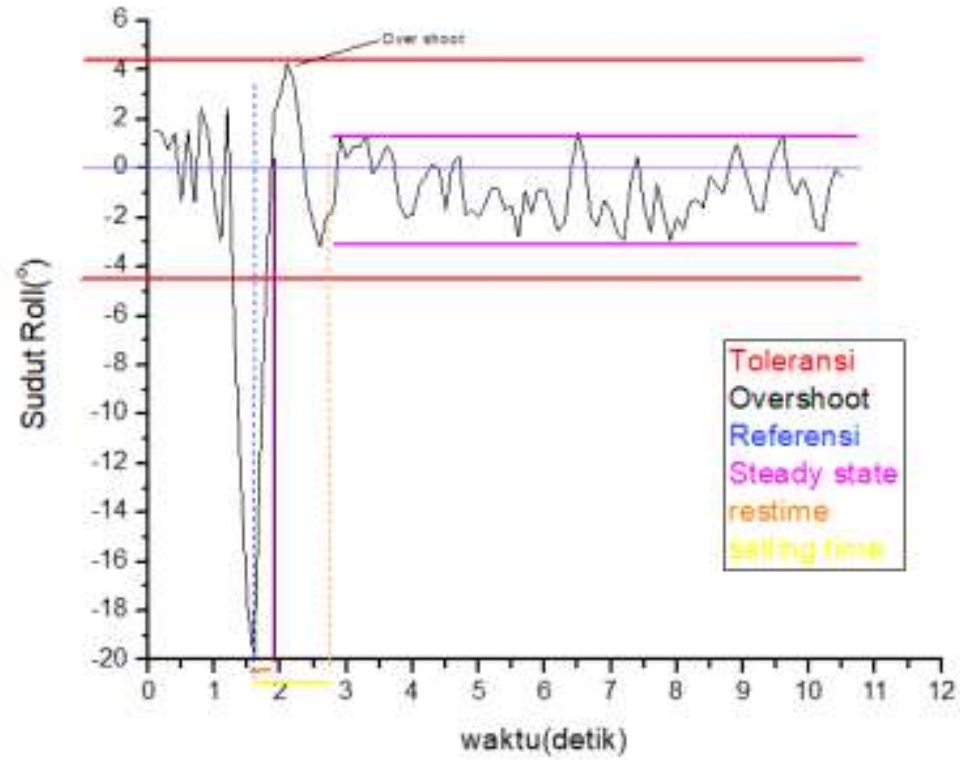

Gambar 8. Karakteristik Gerak Longitudinal

Berdasarkan gambar 3 terlihat sistem mengalami overshoot setelah diberikan gangguan, dan setelah sistem steady terlihat adanya osilasi, keadaan tersebut merupakan keadaan critical stable. Keadaan critical stable akan terus dialami oleh sistem, dan memiliki kecendrungan error mendekati batas atas maupun batas bawah, tetapi masih dalam batas toleransi yaitu $\pm 4,5^{\circ}$. Nilai rata-rata error tersebut merupakan keadaan steady state error yang dimiliki oleh sistem. Berdasarkan hasil pengujian yang telah dilakukan, penerapan metode kendali LQR pada pesawat flying wing mampu meminimalisir gangguan pada sudut roll pesawat, terbukti dengan pesawat mampu kembali ke keadaan stabil. Kemampuan pesawat kembali kekeadaan setpoint membutikan bahwa pengendalian sudut roll tersebut berpengaruh terhadap kemampuan pesawat mempertahankan kestabilan sikap longitudinal. 


\section{KESIMPULAN}

Berdasarkan hasil pengujian dapat ditarik kesimpulan bahwa metode kendali LQR yang diterapkan pada pesawat flying wing untuk mengendalikan sudut roll mampu membuat pesawat mempertahankan sikap longitudinal. Terbukti dengan keadaan pesawat mampu kembali kekeadan semula setelah diberikan gangguan. Pesawat flying wing mampu mempertahankan sikap longitudinal dengan kecendrungan steady state error sebesar $1,37^{\circ}$ dengan batas atas $1,46^{\circ}$ dan batas bawah $-2,64^{\circ}$. Respon sistem yang dialami pesawat masih memenuhi spesfikasi kebutuhan minimal sistem yang diinginkan, yakni overshoot yang terjadi sebesar $4,28^{\circ}$, rise time 0,7 detik, dan setling time 1,3 detik. Pada penelitian selanjutnya perlu ditambahkan pengendalian ketinggian pesawat, agar pesawat mampu mempertahankan kestabilan sikap serta tetap bertahan pada ketinggian.

\section{UCAPAN TERIMA KASIH}

Penelitian ini di danai oleh Universitas Teknokrat Indonesia melalui dana hibah internal sesuai dengan kontrak penelitian tahun anggaran 2020 nomor: 011/UTI/LPPM/E.1.1/VII/2020

\section{DAFTAR PUSTAKA}

[1] R. Zhai, Z. Zhou, W. Zhang, S. Sang, and P. Li, "Control and navigation system for a fixedwing unmanned aerial vehicle," AIP Adv., vol. 4, no. 3, 2014, doi: 10.1063/1.4866169.

[2] M. Dwiyanto et al., "PURWARUPA ROBOT TARI JAIPONG DENGAN MENGGUNAKAN KONTROLER CM-530 JAIPONG DANCE ROBOT PROTOTYPE USING CM-530," vol. 6, no. 1, 2020.

[3] D. B. Widyantara, R. Sumiharto, and S. B. Wibowo, "Purwarupa Sistem Kendali Kestabilan Pesawat Tanpa Awak Sayap Tetap Menggunakan Robust PID," IJEIS (Indonesian J. Electron. Instrum. Syst., vol. 6, no. 2, p. 139, 2016, doi: 10.22146/ijeis.15260.

[4] T. K. Priyambodo, A. E. Putra, and A. Dharmawan, "Optimizing control based on ant colony logic for Quadrotor stabilization," Proc. 2015 IEEE Int. Conf. Aerosp. Electron. Remote Sensing, ICARES 2015, vol. 1, pp. 0-3, 2016, doi: 10.1109/ICARES.2015.7429820.

[5] T. Susanto et al., "Pengendalian Sikap Lateral Pesawat Flying Wing Menggunakan Metode LQR," vol. 7, no. 2, pp. 99-103, 2020.

[6] A. Crasta and S. A. Khan, "EFFECT OF ANGLE OF INCIDENCE ON STABILITY DERIVATIVES OF A WING," pp. 1-6, 1978.

[7] E. Irmawan, P. Mulyono, P. Studi, T. Dirgantara, S. Tinggi, and T. Kedirgantaraan, "KENDALI FUZZY-PID PADA SIKAP LONGITUDINAL DAN SIKAP," vol. 2, no. 2, pp. $1-7,2018$.

[8] C. P. R. Tuuk et al., "Implementasi Pengendali PID Untuk Kestabilan Posisi Terbang Wahana Tanpa Awak," vol. 7, no. 1, pp. 53-62, 2018.

[9] C. Mbaocha C, T. Obiora Valentine, and I. Ezenugu, "STABILITY ANALYSIS AND CONTROLLER DESIGN FOR THE ROLL ANGLE CONTROL OF AN AIRCRAFT," IJAET, vol. 9, no. 4, pp. 435-442, 2016.

[10] E. Irmawan and E. E. Prasetiyo, "Kendali Adaptif Neuro Fuzzy PID untuk Kestabilan Terbang Fixed Wing UAV ( Adaptive Control of Neuro Fuzzy PID for Fixed Wing UAV," vol. 9, no. 1, pp. 73-78, 2020.

[11] L. M. Argentim, W. C. Rezende, P. E. Santos, and R. A. Aguiar, "PID, LQR and LQR-PID on a quadcopter platform," 2013 Int. Conf. Informatics, Electron. Vision, ICIEV 2013, no. February 2015, 2013, doi: 10.1109/ICIEV.2013.6572698.

[12] O. A. Dhewa, A. Dharmawan, and T. K. Priyambodo, "Model of Linear Quadratic Regulator ( LQR ) Control Method in Hovering State of Quadrotor," vol. 9, no. 3, pp. 135-143, 1843.

[13] Y. Y. Nazaruddin, F. Franky, and I. G. N. A. Indra Mandala, "Optimisasi Pengontrol Lqr Menggunakan Algoritma Stochastic Fractal Search,” pp. 235-240, 2019, doi: 10.5614/sniko.2018.27. 